\title{
POSITIVE LEADERSHIP - ATTEMPT TO CLARIFICATION AND ASSESSMENT OF NOVELTY
}

\author{
Przemystaw Zbierowski \\ University of Economics in Katowice, Katowice, Poland \\ e-mail: przemyslaw.zbierowski@ue.katowice.pl
}

\begin{abstract}
Purpose: The paper attempts to clarify the concept of positive leadership. Over the last decade a couple of models of positive leadership have been produced. The paper is purely conceptual its objective is to introduce some order and attempt to clarify what positive leadership really is.

Methodology/approach: The method used in the paper is literature review. The main body of the paper presents three positive leadership concepts: fundamental state of leadership, authentic leadership and positive deviance. They are described and compared along with looking for similarities and causal relationships between them and former leadership concepts: transformational leadership and servant leadership.
\end{abstract}

Findings: There are quite a few similarities and causal relationships between positive and former leadership concepts: self-awareness that is the fundamental issue in both authentic leadership and fundamental state of leadership is very closely linked to transformational leadership and servant leadership. Moreover, the whole concept of servant leadership is very close to positive way of organizing.

Implications for future research: By introducing some order in the field of positive leadership the paper opens the space for future research that might more accurately address complex relationships of positive leaders.

Value of the paper: Even though positive leadership has received some attention recently, this is the first paper to consider a variety of approaches and to underline the similarities, differences and possible causal relationships among them.

Keywords: positive organizational scholarship, positive leadership, authentic leadership, fundamental state of leadership, positive deviance, transformational leadership, servant leadership

Paper type: Conceptual paper

\section{Introduction}

Some time ago I was asked by one of the fellow researchers to answer a couple of questions on positive leadership. One of them was: 'Do you agree that positive leadership is a new paradigm in management science?'. Personally, I think that the 
POSITIVE

LEADERSHIP -

ATTEMPT

Przemysław Zbierowski

answer is 'no', however that and other questions catalyzed my thinking on positive model of leadership. As it turns out, while leadership is one of the leading issues in positive organizational scholarship (POS), there has been a lot of confusion and chaos in that regard. Moreover, rapid development of positive leadership theories has been observed in the last decade and a half since the statement that "the understanding, developmental process, and implementation of needed positive leadership still remains largely underresearched by both the leadership and recently emerging positive psychology fields" (Luthans and Avolio, 2003). Therefore, the objective of the paper is to introduce some order and attempt to clarify what positive leadership really is. Even though it received much attention recently (Lis et al., 2014; Zbierowski and Góra, 2014) I argue that further conceptualization is necessary.

The paper presents the concepts of positive leadership that were proposed during last decade and a half. Its purpose is to clarify the concept of positive leadership, find some common components of various concepts and try to assess the level of novelty of positive leadership approaches. The main body of the paper presents three positive leadership concepts: fundamental state of leadership, authentic leadership and positive deviance. As points of reference I present two models of leadership developed before the birth of POS: transformational leadership and servant leadership. The paper is purely theoretical therefore no research results are presented. The research was carried out within research project 2014/13/B/HS4/01618 funded by National Science Centre, Poland.

\section{Disorder in positive leadership domain}

Leadership is one of the leading topics in positive organizational scholarship. However, a couple of partly competing and partly supplementing each other theories have been developed in the last decade and a half that introduces some degree of disorder. The most widespread approach is that of authentic leadership. It was also the only positive leadership theory included in original POS foundation book by Cameron, Dutton \& Quinn (2003): "this is the only chapter in this book on positive organizational scholarship that deals directly with leadership, and there are no entries in the recently published Handbook of Positive Psychology" (Luthans and Avolio, 2003).

Authenticity itself is one of the pillars of positive organizational scholarship. All the other phenomena discussed within POS have no value and meaning if they are not true and authentic. POS researchers trace back authenticity to ancient times and modernism. Positive psychologists conceive authenticity as both owning one's personal experiences (thoughts, emotions, beliefs) and acting in accord with the true self (behaving and expressing what you really think and believe) (Harter, 2002). Therefore, authentic leadership is purely based on authenticity, authentic leaders do not try to coerce or even rationally persuade associates, but rather the 
leader's authentic values, beliefs, and behaviors serve to model the development of associates.

Authentic leadership is an approach to leadership that emphasizes building the leader's legitimacy through honest relationships with followers which value their input and are built on an ethical foundation. Generally, authentic leaders are positive people with truthful self-concepts who promote openness. By building trust and generating enthusiastic support from their subordinates, authentic leaders are able to improve individual and team performance. Luthans and Avolio (2003) provide a wide range of characteristics of authentic leaders. They are confident, hopeful, optimistic, resilient, transparent, moral/ethical, future-oriented and associate building. However, perhaps the most robust model of authentic leadership was proposed by Walumbwa, Avolio, Gardner, Wernsing and Peterson (2008). They highlight and introduce a measure of four principles of authentic leadership: (1) Self-awareness: An ongoing process of reflection and re-examination by the leader of own strength, weaknesses, and values; (2) Relational transparency: Open sharing by the leader of own thoughts and beliefs, balanced by a minimization of inappropriate emotions; (3) Balanced processing: Solicitation by the leader of opposing viewpoints and fair-minded consideration of those viewpoints; and (4) Internalized moral perspective: A positive ethical foundation adhered to by the leader in relationships and decisions that is resistant to outside pressures.

Another positive concept of leadership that was created a little bit later by Quinn (2005) and is more difficult to grasp is fundamental state of leadership. The essence of it is answering four questions: "Am I results centered? (Am I willing to leave my comfort zone to make things happen?) Am I internally directed? (Am I behaving according to my values rather than bending to social or political pressures?) Am I other focused? (Am I putting the collective good above my own needs?) Am I externally open? (Am I receptive to outside stimuli that may signal the need for change?)" (Quinn, 2005). Quinn claims that "asking and answering these questions tends to change the being state. New feelings, thoughts, behaviors, and techniques then emerge. The person makes deep change and exerts new patterns of influence." (Quinn and Anding, 2005).

However, the critical question in reaching fundamental state of leadership is: Who am I? (What are my values? What would I never compromise?). In this sense fundamental state of leadership draws from emotional intelligence as well where self-awareness is the basic component. Also other focus is based on one of the components of emotional intelligence - empathy.

Quinn (2005) opposes fundamental state of leadership to ordinary state. He also argues that "people who observe excellence from the normal state see only what their conceptual tools allow them to see. (...) Normal thinking, based on the assumptions of transaction and analyses is going to capture the part and not the 
POSITIVE LEADERSHIP ATTEMPT

Przemysław Zbierowski

whole. Normal thinking lacks the requisite variety, the complexity to capture what is there." (Quinn and Anding, 2005). Therefore, fundamental state of leadership should be treated as a higher state of awareness, that, however, can be achieved by combining four components: (1) results orientation, (2) internal direction, (3) other focus, and (4) external openness. Two more attributes of fundamental state of leadership should be noticed. First, Quinn argues that it might not be fully conscious. People could enter fundamental state of leadership without even knowing it. Second, it is a temporary state. People enter and exit it as victims of entropy.

The final concept that can be qualified as positive leadership theory is positive deviance, as it has been presented in the book titled "Positive leadership" (Cameron, 2008). Originally it was created as an approach to behavioral and social change based on the observation that in any community, there are people whose uncommon but successful behaviors or strategies enable them to find better solutions to a problem than their peers, despite facing similar challenges and having no extra resources or knowledge than their peers. These individuals are referred to as positive deviants (Tuhus-Dubrow, 2009). To augment positive deviance from the individual to the firm level, the operational definition of corporate deviance consists of three specific and measurable components: intentionality, departure from referent group norms, and of either a harmful or an honorable nature. Positive deviant behavior, by definition, has to be "voluntary, purposeful, and discretionary, rather than forced or coerced" (Spreitzer and Sonnenshein, 2004).

The most comprehensive model of positive deviance was presented by Cameron (2008). He states that positive leadership: (1) refers to the facilitation of positively deviant performance, (2) refers to an affirmative bias, and 93) focuses on facilitating the best of the human condition, or on fostering virtuousness. Cameron also presents four leadership strategies that enable positive deviance: (1) positive climate (fostering compassion, forgiveness and gratitude), (2) positive relationships (building energy networks and reinforcing strengths), (3) positive communication (obtaining best-self feedback and using supportive communication), and (4) positive meaning (affecting human well-being, connecting to personal values, highlighting extended impact and building community) (Figure 1). Enhancing one of the strategies tends to positively impact the other three.

\section{Similarity to previous leadership concepts}

A careful analysis of the dimensions of authentic leadership and fundamental state of leadership brings to a conclusion that the concept partly overlaps with some previous approaches such as transformational leadership or servant leadership. Transformational leadership theory stresses the fact, that leadership is a process by which a person interacts with others and is able to create a relationship that results 


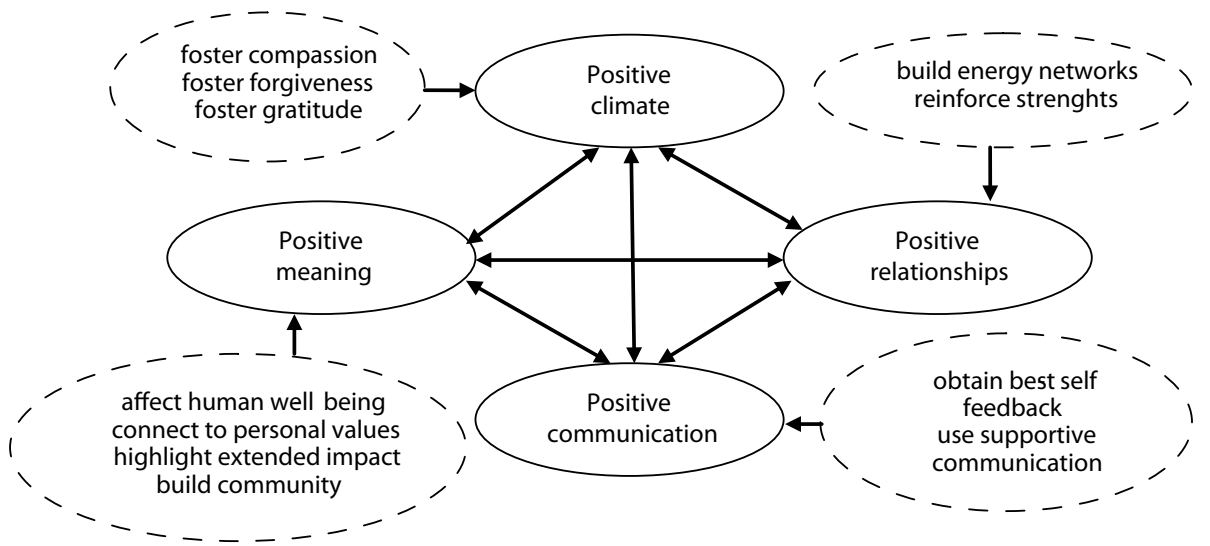

POSITIVE LEADERSHIP -

ATTEMPT

Przemysław Zbierowski

Figure 1. Four leadership strategies that enable positive deviance (Cameron,

2008)

in a high degree of trust, that will later result in an increase of motivation, both intrinsic and extrinsic of both leaders and followers. The core of transformational leadership theories is the assumption that leaders transform their followers (instead of just transacting with them as in transactional theories) through their inspirational nature and charismatic personality. Rules and regulations are flexible, guided by group norms. These attributes provide a sense of belonging for the followers as they can easily identify with the leader and its purpose. Transformational leadership theory rests on the assertion that certain leader behaviors can arouse followers to a higher level of thinking (Bass, 1985; Burns, 1978). By appealing to followers' ideals and values, transformational leaders enhance commitment to a well-articulated vision and inspire followers to develop new ways of thinking about problems (Piccolo and Colquitt, 2006).

The most widespread model of transformational leadership was proposed by Bass (1985). He was interested in the extent to which a leader influences followers. Followers go after a leader because of trust, honesty, and other qualities and the stronger these are, the greater loyalty they have for the leader. The leader transforms the followers because of having these qualities. Not only is the leader a role model but exhorts the following to challenging the existing order, the revolutionary being a stark example of this. While the leader may have democratic motives in mind, he can assume a transaction leadership style at the same time, directing the followers to do things. Bass stressed following aspects of transformational leadership: (1) Individual consideration is the degree to which leaders attend to followers' needs, act as mentors or coaches, and listen to followers' concerns. Individual consideration, where there is an emphasis on what a group member needs. The leader acts as a role model, mentor, facilitator, or teacher to bring a follower into the group and be motivated to do tasks. (2) Intellectual stimulation is the degree to which leaders challenge assumptions, 
POSITIVE

LEADERSHIP -

ATTEMPT

Przemysław Zbierowski

take risks, and solicit followers' ideas. Intellectual stimulation is provided by a leader in terms of challenge to the prevailing order, task, and individual. Leader seeks ideas from the group and encourages them to contribute. learn, and be independent. The leader often becomes a teacher. (3) Inspirational motivation is the degree to which leaders articulate visions that are appealing to followers. Inspiration by a leader means giving meaning to the follows of a task. This usually involves providing a vision or goal. The group is given a reason or purpose to do a task or even be in the organization. The leader will resort to charismatic approaches in exhorting the group to go forward. (4) Idealized influence is the degree to which leaders behave in charismatic ways that cause followers to identify with them. Idealized influence refers to the leader becoming a full-fledged role model, acting out and displaying ideal traits of honesty, trust, enthusiasm and pride.

Servant leadership philosophy was founded by Greenleaf in the essay "The Servant As Leader". Greenleaf, a practitioner with a forty-year career in AT\&T, compiled his observations to stimulate dialogue and build a better, more caring society. He described himself as a lifelong student of organizations and how things get done (1977). Although Greenleaf never formally defined servant-leadership, others have described it as valuing individuals and developing people, building community, practicing authenticity, and providing leadership that focuses on the good of those who are being led and those whom the organization serves. The strength of servant-leadership in encouraging follower learning, growth, and autonomy "suggests that the untested theory will play a role in the future leadership of the learning organization" (Bass, 2000). Liden, Wayne, Zhao and Henderson (2008) developed a multidimensional measure and multi-level assessment of servant leadership consisting of seven dimensions: (1) emotional healing - being sensitive to the personal setbacks of followers, (2) creating value for the community, such as encouraging followers to engage in volunteer activities that benefit local communities, (3) conceptual skills, or the problemsolving abilities and task knowledge that are prerequisites for providing help to followers, (4) empowering, (5) helping subordinates grow and succeed, (6) putting subordinates first, and (7) behaving ethically.

Careful analysis of the content of authentic leadership (AL), fundamental state of leadership (FSL), positive deviance (PD) and former concepts of leadership brings to a conclusion that positive models draw from transformational leadership (TL) and servant leadership (SL). I argue that self-awareness (AL, FSL) is the critical antecedent of idealized influence (TL). Leaders can become role-models only when they are aware of their own strengths, weaknesses, values and emotions. That lets them achieve an understanding of their drivers that are then transmitted to the followers. Self-awareness is also important for behaving ethically (SL) as it demands the extended and aware knowledge of one's moral and ethical system. 
Also relational transparency (AL) is close to idealized influence (TL) as followers are more likely to use the role model when they feel it is genuine. Relational transparency is also linked to some of the dimensions of servant leadership: emotional healing and helping subordinates grow and succeed as they can only be achieved in close and transparent relationship. Balanced processing (AL) is related to individual consideration (TL) - approaching followers individually and taking their views into account. Finally, internalized moral perspective (AL) is critical for behaving ethically (SL).

Also fundamental state of leadership is linked to previous concepts. Internal direction (FSL) is necessary for idealized influence (TL). Other focus (FSL) is linked with individual consideration (TL), but more closely with emotional healing, creating value for the community, empowering, helping subordinates to grow and succeed and putting subordinates first. External openness (FSL) is linked to individual consideration (TL), but also to empowering, helping subordinates grow and succeed and putting subordinates first. To sum up, positive approaches to leadership - authentic leadership and fundamental state of leadership draw from previous concepts, partly supplementing them, partly supporting them and partly using their dimensions more or less directly.

Further analysis of three positive leadership approaches: authentic leadership, fundamental state of leadership and positive deviance reveals that they might not be placed at the same level in leadership process. More specifically, I argue that authentic leadership and fundamental state of leadership are two models of leadership itself, but positive deviance is more an outcome of those processes, even though it has been presented in the book titled "Positive leadership" (Cameron, 2008). That is because positive deviance is defined in categories of results, as the final state of organization that should be achieved by positive leadership. Therefore, there arises the question of possible impact of transformational leadership and servant leadership on positive deviance. Careful analysis of content of all three models brings to a conclusion that transformational leadership should matter more for positive relationships and positive communication while servant leadership should reinforce positive climate and positive meaning. Transformational leadership is directed at developing full potential of employees, reinforcing strengths, using supportive communication. Building energy networks is also closely connected to individual consideration, intellectual stimulation, idealized influence and inspirational motivation. All those activities involve transmitting positive energy to followers that results in positive relationships and positive communication. On the other hand, some of dimensions of servant leadership are directly linked to activities included in the model of positive deviance, such as emotional healing (SL) that is connected to compassion, forgiveness and gratitude (PD), creating value for community (SL) is directly reflected in building community (PD), empowering (SL) raises well-being (PD), and behaving ethically (SL) helps to 
POSITIVE

LEADERSHIP ATTEMPT

Przemysław Zbierowski connect to personal values. As a whole servant leadership should therefore result in building positive climate and positive meaning among followers.

\section{Conclusions}

The purpose of the paper is to clarify the concept of positive leadership. It seems that two of the models: authentic leadership and fundamental state of leadership are partly overlapping. In both of them fundamental issue is self-awareness. Therefore, it seems that both models refer in a way to emotional intelligence, where also self-awareness is the fundament. It must be said though that in emotional intelligence self-awareness concerns mainly emotions, in authentic leadership and fundamental state of leadership it span is wider, covering strengths, weaknesses and values. Moreover, both authentic leadership and fundamental state of leadership stress building meaningful relationship with followers and managing them through those relationships. Therefore, it can be said that those two models are quite close to each other, although authentic leadership puts more emphasis on honest relationships and fundamental state of leadership on balancing internal direction and openness to followers' points of view and ideas.

Analysis of three positive leadership approaches: authentic leadership, fundamental state of leadership and positive deviance reveals that they are possibly not placed at the same level in leadership process. Positive deviance is defined in categories of results, as the final state of organization that should be achieved by positive leadership. Therefore, I argue that both authentic leadership and fundamental state of leadership might lead to achieving positive deviance. This specific kind of climate, meaning, relationships and communication is achievable by building honest and close relationships with followers, but more importantly, by managing energy that is strongly emphasized in positive deviance concept and by Kim Cameron in his other works and public speeches.

The central question asked in this paper was of the similarity of positive leadership models to former leadership concepts: transformational leadership and servant leadership. The answer is that there are many similarities and possible cause-and-effect relationships. Especially self-awareness that is the fundamental issue in both authentic leadership and fundamental state of leadership is very closely linked to transformational leadership and servant leadership. Among transformational leadership dimensions especially individual consideration and idealized influence are linked to positive approaches to leadership. Moreover, the whole concept of servant leadership is very close to positive way of organizing. Liden, Wayne, Liao and Meuser state that "servant leadership represents a positive approach to organizational behavior, the study of which refers to the application of positively oriented human resource strengths and psychological capacities that can be measured, developed, and effectively managed for performance improvement in today's workplace" (2014). 
Going further, if positive leadership models are similar to previous ones there arises a question of their possible contribution to leadership research. In my opinion it is potentially significant, as they shift the balance from building performance of followers (transformational leadership) and supporting their growth and well-being (servant leadership) to truly in-depth relationships built on honesty (authentic leadership), full understanding of oneself and one's relationships with followers (fundamental state of leadership) and transfer of energy to achieve not only positive leadership, but holistic positive shape of organization (positive deviance). Of course, future impact of positive leadership models on research will be dependent on further clarification of those concepts (especially fundamental state of leadership), including their proper operationalization.

Having said that, a question of future research directions is worth asking. In my opinion the research should be continued in three areas that partly overlap and combined will allow to draw big picture of positive leadership. The first area are possible interconnections and causal relationships among various models of leadership and their dimensions that will introduce clarity in positive leadership domain. Secondly, an important issue concerns possible antecedents and consequences of positive leadership. The former most possibly include psychological capital and emotional intelligence. Finally, the research should concern putting positive leadership in broader context of other positive issues on various levels of organizational life. Only approaching positive leadership from this perspective will allow to build a holistic landscape of organizational positivity.

\section{References}

Bass, B. (2000), "The future of leadership in learning organizations", Journal of Leadership Studies, Vol. 7 No. 3, pp. 18-40. DOI: http://dx.doi.org/10.1177/107179190000700302

Bass, B. M. (1985), Leadership and performance beyond expectations, New York: Free Press, New York.

Burns, J. M. (1978), Leadership, New York: Harper \& Row, New York.

Cameron, K. S. (2008), Positive leadership. Strategies for extraordinary performance, Berrett Koehler Publishers, Inc., San Francisco.

Cameron, K. S., Dutton, J. E., Quinn, R. E. (2003), Positive organizational scholarship. Foundations of a new discipline, Berrett-Koahler Publishers, Inc., San Francisco.

Greenleaf, R. (1977), Servant-leadership: A journey into the nature of legitimate power and greatness, Paulist Press, New York.

Harter, S. (2002), "Authenticity”, in: Snyder, C. R., Lopez, S. J. (Eds.), Handbook of positive psychology, Oxford University Press, Oxford, pp. 382-394.

Liden, R. C., Wayne, S. J., Zhao, H., Henderson, D. (2008), "Servant leadership: Development of a multidimensional measure and multi-level assessment", Leadership Quarterly, Vol. 19 No. 2, pp. 161-177. DOI: http://dx.doi.org/10.1016/j. leaqua.2008.01.006 
POSITIVE LEADERSHIP ATTEMPT

Przemysław Zbierowski
Liden, R. C., Wayne, S. J., Liao, Ch., Meuser, J. D. (2014), "Servant leadership and serving culture: Influence on individual and unit performance", Academy of Management Journal, Vol. 57 No. 5, pp. 1434-1452. DOI: http://dx.doi.org/10.5465/amj.2013.0034

Lis, A., Glińska-Neweś, A., Kalińska, M. (2014), "The role of leadership in shaping interpersonal relationships in the context of positive organizational scholarship", Journal of Positive Management, Vol. 5, No. 4, pp. 28-49.

Luthans, F., Avolio, B. (2003), “Authentic leadership development”, in: Cameron, K. S., Dutton, J. E., Quinn, R. E. (Eds.), Positive organizational Scholarship. Foundations of a new discipline, Berrett-Koahler Publishers, Inc., San Francisco, pp. 241-258.

Piccolo, R. F., Colquitt, J. A. (2006), "Transformational leadership and job behaviors: The mediating role of core job characteristics", Academy of Management Journal, Vol. 49 No. 2, pp. 327-340. DOI: http://dx.doi.org/10.5465/AMJ.2006.20786079

Quinn, R. E. (2005), "Moments of greatness: Entering the fundamental state of leadership", Harvard Business Review, July-August, pp. 75-83.

Quinn, R. E., Anding, J. M. (2005), “An Interview with Robert E. Quinn Entering the fundamental state of leadership: Reflections on the path to transformational teaching", Academy of Management Learning \& Education, Vol. 4 No. 4, pp. 487-495.

Spreitzer, G. M., Sonenshein, S. (2003), "Positive deviance and extraordinary organizing", in: Cameron, K. S., Dutton, J. E., Quinn, R. E. (Eds.), Positive organizational Scholarship. Foundations of a new discipline, Berrett-Koahler Publishers, Inc., San Francisco, pp. 207-224.

Spreitzer, G. M., Sonnenschein, S. (2004), "Toward the construct definition of positive deviance", American Behavioral Scientist, Vol. 47 No. 6, pp. 828-847. DOI: http:// dx.doi.org/10.1177/0002764203260212

Tuhus-Dubrow, R. (2009), "The Power of Positive Deviants: A promising new tactic for changing communities from the inside", Boston Globe, November, pp. 29-31.

Walumbwa, F. O., Avolio, B. J., Gardner, W. L., Wernsing, T. S., Peterson, S. J. (2007), "Authentic leadership: Development and validation of a theory-based measure", Journal of Management, Vol. 34, pp. 89-126. DOI: http://dx.doi. org/10.1177/0149206307308913

Zbierowski, P., Góra, K. (2014), "Positive leadership: Its nature, antecedents and consequences", Journal of Positive Management, Vol. 5 No. 1, pp. 85-99. DOI: http:// dx.doi.org/10.12775/JPM.2014.008 